\title{
Soil age and soil organic carbon content shape biochemical responses to multiple freeze-thaw events in soils along a postmining agricultural chronosequence
}

\author{
Christoph Rosinger (i) $\cdot$ Michael Bonkowski $($ i)
}

Received: 3 December 2020/ Accepted: 24 May 2021 / Published online: 7 June 2021

(C) The Author(s) 2021

\begin{abstract}
Freeze-thaw (FT) events exert a great physiological stress on the soil microbial community and thus significantly impact soil biogeochemical processes. Studies often show ambiguous and contradicting results, because a multitude of environmental factors affect biogeochemical responses to FT. Thus, a better understanding of the factors driving and regulating microbial responses to FT events is required. Soil chronosequences allow more focused comparisons among soils with initially similar start conditions. We therefore exposed four soils with contrasting organic carbon contents and opposing soil age (i.e., years after restoration) from a postmining agricultural chronosequence to three consecutive FT events and evaluated soil biochgeoemical responses after thawing. The major microbial biomass carbon losses occurred after the first FT event, while microbial biomass $\mathrm{N}$ decreased more steadily with subsequent
\end{abstract}

Responsible Editor: Stuart Grandy.

C. Rosinger $(\varangle) \cdot$ M. Bonkowski

Terrestial Ecology Group, Institute of Zoology, University of Cologne, Zülpicher Straße 47b, 50476 Cologne,

Germany

e-mail: christoph.rosinger@boku.ac.at

Present Address:

C. Rosinger

Institute of Soil Research, Department of Forest and Soil

Sciences, University of Natural Resources and Life

Sciences (BOKU), Peter Jordan Straße 82, 1190 Vienna,

Austria
FT cycles. This led to an immediate and lasting decoupling of microbial biomass carbon:nitrogen stoichiometry. After the first FT event, basal respiration and the metabolic quotient (i.e., respiration per microbial biomass unit) were above pre-freezing values and thereafter decreased with subsequent FT cycles, demonstrating initially high dissimilatory carbon losses and less and less microbial metabolic activity with each iterative FT cycle. As a consequence, dissolved organic carbon and total dissolved nitrogen increased in soil solution after the first FT event, while a substantial part of the liberated nitrogen was likely lost through gaseous emissions. Overall, high-carbon soils were more vulnerable to microbial biomass losses than low-carbon soils. Surprisingly, soil age explained more variation in soil chemical and microbial responses than soil organic carbon content. Further studies are needed to dissect the factors associated with soil age and its influence on soil biochemical responses to FT events.

Keywords Agricultural post-mining chronosequence $\cdot$ Basal respiration . Biogeochemistry $\cdot$ Metabolic quotient $\cdot$ Microbial biomass $\cdot$ Multiple freeze-thaw
Abbreviations
C Carbon
DOC Dissolved organic carbon
FT Freeze-thaw 
MB-C Microbial biomass C

MB-N Microbial biomass N

$\mathrm{N} \quad$ Nitrogen

$\mathrm{qCO}_{2} \quad$ Metabolic quotient

SOC Soil organic carbon

TDN Total dissolved nitrogen

\section{Introduction}

Freeze-thaw (FT) events have a major impact on soil biogeochemical processes (Bardgett et al. 2008; Congreves et al. 2018). Soil microbial dynamics are significant drivers of these biogeochemical responses (Sharma et al. 2006; Henry 2007), as their ecophysiology is greatly affected by FT (Schimel and Mikan 2005; Schimel et al. 2007; Mooshammer et al. 2017; Miura et al. 2019). Although soil microbes can physiologically adapt to freezing (or rather nearfreezing) temperatures, for example by $(i)$ upregulating protein synthesis, (ii) increasing membrane fluidity (through changes in the fatty acid composition), (iii) taking up or producing cryo-protecting osmolytes or (iv) regulating specific metabolic pathways (reviewed e.g. in Shivaji and Prakash 2010; Margesin and Miteva 2011), empirical evidence shows that a considerable portion of the soil microbial biomass can be lost after FT events (Feng et al. 2007; Song et al. 2017; Han et al. 2018). This die-back can be caused by physiological stress imposed by freezing itself or by the subsequent thawing process, when soil microbes must rapidly reverse their freezing adaptations to prevent cell rupture (Schimel et al. 2007). In any case, increased levels of labile organic compounds are commonly recorded after FT in soils (Matzner and Borken 2008). Depending on the prevailing environmental conditions, these nutrients can either be lost through leaching, through gaseous emissions, or metabolized by the remaining viable microbes, thus explaining the commonly observed peaks in $\mathrm{CO}_{2}$ and $\mathrm{N}_{2} \mathrm{O}$ evolving from soils after FT (Joseph and Henry 2008; Matzner and Borken 2008; Song et al. 2017; Congreves et al. 2018). Soil carbon (C) and nitrogen (N) losses after FT can be substantial (Matzner and Borken 2008; Congreves et al. 2018) and have been inherently linked to soil microbial biomass dynamics (Christensen and Christensen 1991; Hermann \& Witter 2002; Matzner and Borken 2008; Risk et al.
2013). For example, Hermann and Witter (2002) could show that around $65 \%$ of the C flush after FT was attributed to $\mathrm{C}$ derived from soil microbial biomass. Moreover, Sharma et al. (2006) found increased activity and expression of denitrifying genes of the soil microbial community after FT, suggesting that increased $\mathrm{N}_{2} \mathrm{O}$ emissions after FT were a result of increased microbial activity. Therefore, a better understanding of the mechanisms that drive microbial responses to FT events is crucial. This is particularly the case as extreme weather events-such as drought or freezing - are suggested to have a greater impact on microbial-mediated ecosystem responses than overall future changes in temperature and precipitation (Bardgett et al. 2008).

Several factors influence the impact of FT effects on soil biogeochemistry. For example, physical and chemical attributes such as soil organic matter content, soil $\mathrm{pH}$, or soil pore size influence the response of soil microbial biomass to FT (Yanai et al. 2004; Freppaz et al. 2007; Song et al. 2017). Other important aspects governing microbial responses to FT are the intensity, duration and frequency of FT events (Feng et al. 2007; Schmitt et al. 2008; Han et al. 2018). Given this multifactorial complexity, we require a better and comprehensive mechanistic understanding of the drivers of soil chemical and microbial responses to FT events.

We therefore examined the effect of multiple FT events on soils from a 23-year postmining agricultural chronosequence in Western Germany. Due to highly comparable initial soil conditions, chronosequences allow more targeted investigations of microbial responses to FT along gradients of soil organic C (SOC) formation (Walker et al. 2010) and are well suited to disentangle the important driving factors. For example, SOC content may influence responses through potentially increased porosity and water retention capacity in high-SOC soils (Yang et al. 2013). Soil age was recently identified as an important local-scale driver of ecosystem properties such as soil $\mathrm{pH}$, soil N:P and C:P ratios and total soil C stocks (Delgado-Baquerizo et al. 2020). Moreover, a history of soil freezing selects for more frost-tolerant and physiologically adapted microbial communities (Walker et al. 2006; Garcia et al. 2020), suggesting that soil age might be important too. Accordingly, we used four different soils of varying SOC contents (from 0.39 to $1.04 \% \mathrm{C}$ ) and time after soil restoration 
(from 4 to 23 years; from now on referred to as 'soil age') and exposed these to three severe FT cycles. We analysed dissolved organic $\mathrm{C}$ (DOC), total dissolved $\mathrm{N}$ (TDN), microbial biomass C (MB-C) and N (MB-N), as well as respiratory responses before freezing and $36 \mathrm{~h}$ after each respective FT event. We hypothesized that MB-C and MB-N will decrease with consecutive exposure to FT, with subsequent increases in DOC and TDN. Moreover, we hypothesized that SOC content and soil age shape biochemical and microbial responses to FT.

\section{Materials and methods}

Study site

The sampling site is located in the open-cast mining area Gartzweiler around $6 \mathrm{~km}$ south of Mönchengladbach $\left(6^{\circ} 15^{\prime} 0^{\prime \prime} \mathrm{E}\right.$ to $6^{\circ} 21^{\prime} 0^{\prime \prime} \mathrm{E} ; 50^{\circ} 50^{\prime} 5^{\prime \prime} \mathrm{N}$ to $50^{\circ} 53^{\prime}$ $\left.0^{\prime \prime} \mathrm{N}\right)$. Mean annual temperature and precipitation is $9.8{ }^{\circ} \mathrm{C}$ and $829 \mathrm{~mm}$, respectively. Lignite is extracted in this open-cast mining site by RWE Power AG (Essen, Germany) after removing topsoil and parent material. After lignite extraction, loess material from topsoil (characterized as Luvisol) and parent material (unweathered loess from the Weichselian glaciation period; Lucas et al. 2019) are mixed (in a 1:100 ratio) and used as the basis for subsequent agricultural recultivation, thus creating a 56-year agricultural postmining chronosequence. The soil texture is a silty clay loam with around $65 \%$ silt and $31 \%$ clay (Lucas et al. 2019). The bulk density in soil layers not affected by soil tillage is around $1.6 \mathrm{~g} \mathrm{~cm}^{-3}$ (Pihlap et al. 2019). Reclaimed soils typically received an initial fertilization of 60,120 and $180 \mathrm{~kg}$. ha ${ }^{-1}$ of each, $\mathrm{N}$ and $\mathrm{P}$ and $\mathrm{K}$ fertilizer in the first year, and are cultivated for three subsequent years with alfalfa (Medicago sativa) without any further fertilizer or biocide applications. Four to seven years after reclamation, fields typically undergo a wheat and barley crop rotation. Cereals are fertilized with mineral NPK and CAN (Calcium Ammonium Nitrate) fertilizers, and receive in addition in the fourth and seventh year of reclamation $30 \mathrm{tha}^{-1}$ of organic fertilizer (compost), resulting in a total annual fertilization rate of $200,80,60$ and $40 \mathrm{~kg} \mathrm{ha}^{-1}$ of $\mathrm{N}, \mathrm{P}, \mathrm{K}$ and $\mathrm{Mg}$ fertilizer, respectively. After 7 years, fields are returned to the previous owners and are usually managed with a sugar beet-winter wheat crop rotation (Lucas et al. 2019; Pihlap et al. 2019).

According to the German weather service (DWD), soils in the study area typically undergo up to ten FT cycles in the winter period, when soil temperatures typically cycle around the freezing point. However, differences between daily minimum and maximum air temperatures of more than $21{ }^{\circ} \mathrm{C}$ within $72 \mathrm{~h}$ have also been recorded, thus showing that soils in this area are exposed to severe but short temperature differences around the freezing point.

\section{Experimental setup}

Soil samples were taken in July/August 2019 on 8 different agricultural sites along the chronosequence. The crop on all agricultural sites was either barley or wheat. The minimum distance between sites was ca. $500 \mathrm{~m}$. Five soil samples were taken randomly at each sampling site with a minimum distance of $20 \mathrm{~m}$ between replicates. The soil samples themselves consisted of 5 pooled subsamples taken within a $1 \times 1 \mathrm{~m}$ square. Samples were taken from the upper $A_{p}$ horizon to a depth of $10 \mathrm{~cm}$ using a soil sampling auger $(5.5 \mathrm{~cm}$ diameter). Samples were put in plastic bags and brought to the laboratory the same day, where they were sieved to pass $2 \mathrm{~mm}$ and stored at $4{ }^{\circ} \mathrm{C}$ until experimental initiation in January 2020.

In order to analyse soil chemical and microbial responses to multiple FT events, we chose four agricultural soils with SOC contents ranging from 0.39 to $1.04 \%$ (Table 1 ). We deliberately chose soils with similar SOC contents but different soil ages (soils 2 and 3 ) and vice versa (soils 3 and 4) in order to better disentangle SOC content and soil age effects on FT responses. In this study, we chose a harsh freezing treatment at $-21{ }^{\circ} \mathrm{C}$ followed by thawing at $10{ }^{\circ} \mathrm{C}$, which resembles a rather strong cold snap. Therefore, and because we wanted to amplify potential effects, we chose this temperature regime.

For the incubation, the five samples taken per agricultural site were pooled, and ca. $30 \mathrm{~g}$ of fresh soil were weighed into $50 \mathrm{ml}$ plastic tubes with five technical replicates. The water content was set to field capacity with deionized water. Samples were then preincubated in the dark for 21 days at $10{ }^{\circ} \mathrm{C}$. Water content was determined gravimetrically every three days and adjusted as needed. Tubes were loosely covered with a plastic lid to allow gas exchange. At the 
Table 1 Time since restoration (years), soil $\mathrm{pH}$, SOC and total $\mathrm{N}$ contents (\%) of the 4 different soils used in the experiment

\begin{tabular}{lllll}
\hline Soil & Time since restoration (years) & Soil pH & SOC $(\%)$ & Soil N $(\%)$ \\
\hline 1 & 4 & $8.59^{\mathrm{c}}(0.02)$ & $0.39^{\mathrm{a}}(0.003)$ & $0.009^{\mathrm{a}}(0.001)$ \\
2 & 12 & $8.52^{\mathrm{b}}(0.01)$ & $0.77^{\mathrm{b}}(0.005)$ & $0.031^{\mathrm{b}}(0.003)$ \\
3 & 23 & $8.25^{\mathrm{a}}(0.02)$ & $0.76^{\mathrm{b}}(0.004)$ & $0.043^{\mathrm{c}}(0.002)$ \\
4 & 23 & $8.23^{\mathrm{a}}(0.01)$ & $1.04^{\mathrm{c}}(0.007)$ & $0.052^{\mathrm{d}}(0.002)$ \\
\hline
\end{tabular}

Given is the mean \pm 1 SD (in brackets) of three technical replicates that have been analysed for each of the four pooled soil samples. Different letters behind means indicate significant differences $(\mathrm{p}<0.05$; post-hoc Tukey test) between soils

end of the pre-incubation period, a first set of the soil samples were analysed for DOC, TDN, MB-C, MB-N and basal respiration. Immediately after, all soil samples were exposed to severe freezing conditions $\left(-21^{\circ} \mathrm{C}\right)$ for $48 \mathrm{~h}$. After the freezing event, soils were thawed at $10{ }^{\circ} \mathrm{C}$. Exactly $36 \mathrm{~h}$ after the freezing event, the second set of soil samples was analysed for DOC, TDN, MB-C, MB-N and basal respiration. We chose a time period of $36 \mathrm{~h}$ to make sure that all the soil in the tubes was properly thawed by the point of analysis. The remaining soil samples were kept at $10{ }^{\circ} \mathrm{C}$ for 5 days until the next FT cycle. These steps were repeated for two more sets of soil samples, i.e. a total of three FT cycles. Therefore, a total of 80 samples was analysed in this experiment $(4$ soils $\times 5$ technical replicates $\times 4$ treatments (i.e. before freezing and three FT events)).

\section{Soil analysis}

MB-C and MB-N were analysed using the chloroformfumigation extraction (CFE) method (Vance et al. 1987; Witt et al. 2000). Briefly, two subsamples of $5 \mathrm{~g}$ fresh wt soil were taken from each soil sample. One subsample was shaken in $20 \mathrm{ml}$ of $0.5 \mathrm{M} \mathrm{K}_{2} \mathrm{SO}_{4}$ for $30 \mathrm{~min}$ and centrifuged at $4500 \mathrm{rpm}$ for $10 \mathrm{~min}$. Thereafter, $3 \mathrm{ml}$ of the supernatant were transferred into new $15 \mathrm{ml}$ plastic tubes and frozen until further determination of DOC and TDN. The other subsample was fumigated under vacuum (using a desiccator) with $50 \mathrm{ml}$ of ethanol-free chloroform for $24 \mathrm{~h}$ at room temperature prior to extraction (as above). Extracts were analysed on a Multi N/C analyser (2100S, Analytik Jena, Jena, Germany). MB-C and MB-N were calculated as the difference between fumigated and non-fumigated DOC and TDN, respectively. MB$\mathrm{C}$ and MB-N were not corrected by any extraction efficiency coefficients. All results are expressed in $\mu \mathrm{g}$ g dry soil ${ }^{-1}$.

Basal respiration was measured by an automated electrolytic micro-respiratory apparatus (Scheu 1992). Briefly, ca. $4 \mathrm{~g}$ of fresh soil were weighed into glass vessels and connected to the respirometer. The $\mathrm{O}_{2}$ consumption rates were measured at $21{ }^{\circ} \mathrm{C}$ every $30 \mathrm{~min}$ and subsequently converted to $\mathrm{CO}_{2}$ production using the molar gas constant. Basal respiration is expressed in $\mu \mathrm{g} \mathrm{CO}_{2}-\mathrm{C} \mathrm{g}$ dry soil $^{-1} \mathrm{~h}^{-1}$. The metabolic quotient $\left(\mathrm{qCO}_{2}\right)$ was calculated as basal respiration per unit MB-C and is expressed in $\mathrm{mg} \mathrm{CO}_{2^{-}}$ $\mathrm{C} \mathrm{g} \mathrm{MB-C}-1 \mathrm{~h}^{-1}$.

\section{Statistical analysis}

We conducted a one-way multivariate analysis of covariance (MANCOVA) to test for significant differences in DOC, TDN, the DOC:TDN ratio, MB-C, MB-N, the MB-C:N ratio, basal respiration and $\mathrm{qCO}_{2}$ between the time points before freezing and after the first, second and third FT event. FT treatment was used as a fixed factor (from now on referred to as 'FT' or 'FT treatment'), and SOC content and soil age were treated as covariates. We used a SS type III model to test for significant treatment effects as well as significant interactions with SOC content and soil age, respectively. To evaluate the statistical significance of the overall model, the Wilks' lambda distributions $(\lambda)$ and derived F-values, p-values and the partial eta squared $\left(\eta^{2}\right)$ for main and interaction effects are stated. As the freshly recultivated loess material contains carbonates which disaggregate over time in the upper soil horizon of the chronosequence, soil age and soil $\mathrm{pH}$ were negatively correlated $(\mathrm{R}=-0.978, \mathrm{p}=0.022)$. The use of both factors in a single one-way MANCOVA showed that soil age 
( $\mathrm{F}=12.584, \mathrm{p}<0.001$, Wilks' $\lambda=0.014$, partial $\left.\eta^{2}=0.659\right)$ appeared to be the stronger explanatory variable as compared to soil $\mathrm{pH}(\mathrm{F}=9.088$, $\mathrm{p}<0.001$, Wilks' $\lambda=0.03$, partial $\eta^{2}=0.585$ ). Accordingly, we omitted the colinear soil $\mathrm{pH}$ as a covariate. Moreover, SOC and total N were positively correlated $(\mathrm{R}=0.957, \mathrm{p}=0.043)$. Using the same approach as above, the SOC content $(\mathrm{F}=9.206$, $\mathrm{p}<0.001$, Wilks' $\lambda=0.03$, partial $\eta^{2}=0.585$ ) was kept in the model as it had the slightly higher explanatory power compared to the soil $\mathrm{N}$ content ( $\mathrm{F}=9.108, \quad \mathrm{p}<0.001$, Wilks' $\lambda=0.03$, partial $\left.\eta^{2}=0.583\right)$.

Post-hoc Tukey tests using Šidák correction for multiple pairwise comparisons were used to evaluate significant differences across all soils between the respective FT events, while simple post-hoc Tukey tests were applied to evaluate significant differences between FT treatments within soil samples. Moreover, we used linear regression analyses and Pearson correlation coefficients to evaluate the relationship between MB-C and MB-N before freezing and after the first, second and third FT event. We refer to significant differences at the $\mathrm{p}<0.05$ level (with $* \mathrm{p}<0.05$;** $<0.01$; and $* * * \mathrm{p}<0.001$ ). All statistical analyses and figures were conducted in SPSS 26. p-values in the results section refer to both MANCOVA (main and interaction effects) and posthoc statistics.

\section{Results}

Overall, the one-way MANCOVA revealed a strong main effect of the three FT events $\left(F_{1,27}=19.583\right.$, $\mathrm{p}<0.001$ ) on our tested soil chemical and microbial parameters. However, the response to FT events was dependent on $\operatorname{SOC}\left(\mathrm{F}_{2,27}=4.918, \mathrm{p}<0.001\right)$ and soil age $\left(\mathrm{F}_{2,27}=9.323, \mathrm{p}<0.001\right)$, respectively. The detailed test statistics can be found in Table 2 .

\section{Soil chemical responses to FT}

DOC contents in all four soils decreased after the first FT event (by 19.8, 24.2, 21.8 and 5.4\% in soils 1 to 4 , respectively; $\mathrm{p}=0.001$ ), yet increased with the second and third FT event back to initial DOC levels (Fig. 1A, p < 0.01). TDN contents did not change after the first FT event as compared to before FT, but increased after the second FT in soils 2 and 4, and after the third FT event in soils 1 and 3 (Fig. 1B). After three FT events, TDN contents were increased by 78 , 11,16 and $21 \%$ in soils 1 to 4 , respectively, as compared to before freezing $(\mathrm{p}<0.001)$. Overall, DOC:TDN ratios decreased following the three FT events (Fig. 1C). The strongest decrease $(-42.7 \%)$ was recorded in soil 1 (Table 1), which also displayed the highest DOC:TDN ratio $(\mathrm{p}<0.01)$. In soils $2-4$, the DOC:TDN ratio decreased after three FT events by $10-15 \%$. In summary, soil age significantly shaped the response of DOC, TDN and the DOC:TDN ratio to multiple FT, while the SOC content had no significant effect (Table 2, Fig. 1A-C).

\section{Soil microbial responses to FT}

MB-C was strongly affected by the three FT events (Fig. 1D). MB-C dropped sharply already after the first FT $(34,17,21$ and $40 \%$ in soils 1 to 4 , respectively; $p<0.001)$ and remained rather constant following the second and third FT cycles. The magnitude of the decline increased with soil age $(\mathrm{p}<0.001)$ and was less, but significantly dependent on SOC content $(\mathrm{p}<0.05)$. After the third FT event, MB-C had declined to $69,70,72$ and $54 \%$ of prefreezing values in soils 1 to 4 , respectively ( $p<0.001)$. MB-N instead decreased rather steadily with consecutive FT events (Fig. 1E). Declines in MB-N were rather strong, with decreases of 48, 61, 57 and $66 \%$ in soil 1 to 4 , respectively, after the third FT event as compared to before FT ( $<<0.001)$, and not influenced by soil age or $\mathrm{C}$ content. MB-C:N ratios tended to increase with multiple FT, yet overall effects were quite variable and found to be marginal ( $p=0.067$; Fig. 1F). Only between the second and third FT event we noticed a substantial increase of the MB-C:N ratio of 48,87, 56 and $62 \%$ in soils 1 to 4 , respectively ( $\mathrm{p}<0.002$ ). Overall, MB-C responses to multiple FT were dependent on soil age and the SOC content, while neither MB-N nor MB-C:N ratios were significantly affected by soil age or soil $\mathrm{C}$ content (Table 2, Fig. 1D-F).

Linear regression analyses and Pearson correlation coefficients showed a significant positive relationship between MB-C and MB-N before freezing (Fig. 2A), but the correlation disappeared already after the first FT (Fig. 2B), and was not regained after the second (Fig. 2C) and the third FT event (Fig. 2D). 
Table 2 Test statistics of the MANCOVA analysis to evaluate the effect of FT as well as interactions between FT and SOC content (FT * soil SOC) and time since restoration (FT* soil age) on soil and soil biochemical (DOC, dissolved organic C; TDN, total dissolved N) and microbial parameters (MB$\mathrm{C}$, microbial biomass $\mathrm{C}$; MB-N, microbial biomass $\mathrm{N}$; MB-C:N, microbial biomass $\mathrm{C}: \mathrm{N}$ ratio; microbial basal respiration; $\mathrm{qCO}_{2}$, respiratory quotient)

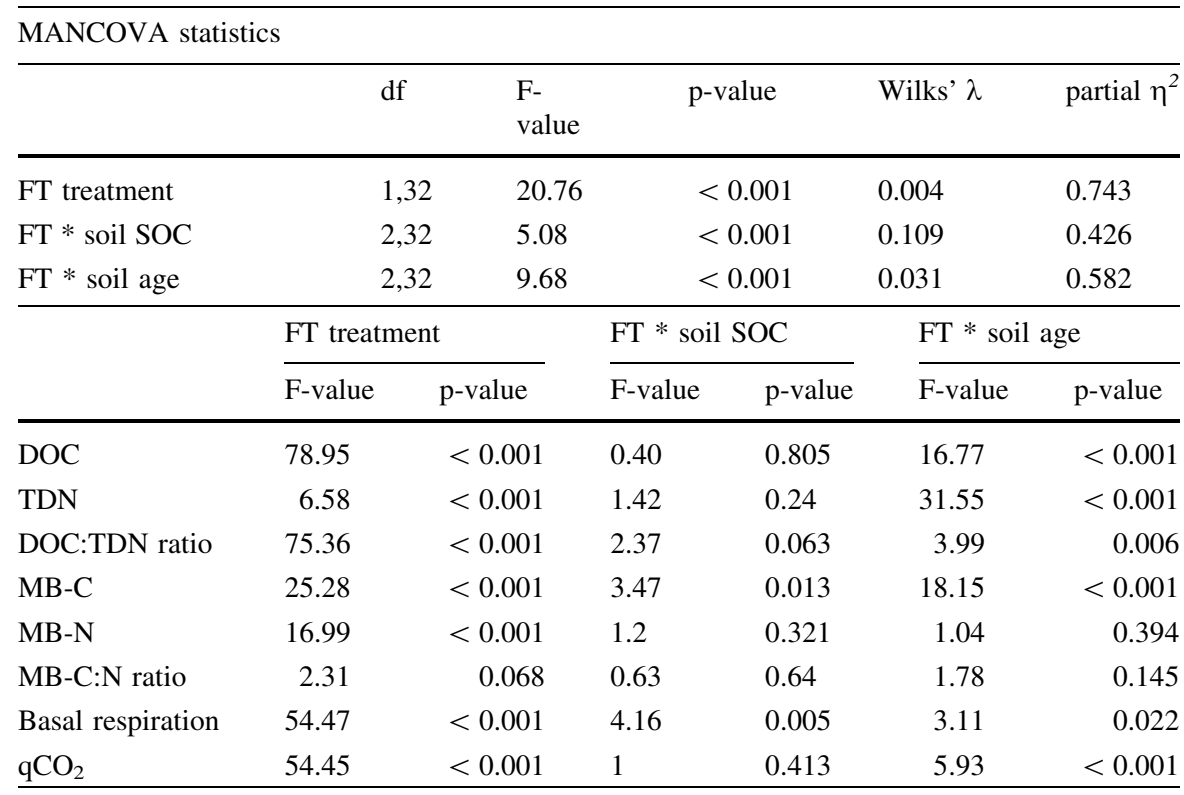

\section{Respiratory responses to FT}

Overall, multiple FT events had a significant impact on basal respiration and the metabolic quotient. Basal respiration initially increased after the first FT event $(p=0.004)$, but then dropped after the second and third FT event (both $\mathrm{p}<0.001$ ) as compared to before freezing (Fig. 3A). After three FT cycles, basal respiration had decreased by $45,59,25$ and $44 \%$ in soils 1 to 4 , respectively, as compared to before freezing. FT responses of $\mathrm{qCO}_{2}$ mimicked basal respiratory responses (Fig. 3B). After the first FT event, $\mathrm{qCO}_{2}$ significantly increased as compared to before freezing ( $\mathrm{p}<0.001$ ); by $95,22,74$ and $84 \%$ in soils 1 to 4, respectively, but after the second and third FT event, the $\mathrm{qCO}_{2}$ decreased to initial levels (in the soils 1,3 and 4 ) or below (in soil 2$)(p<0.001)$. The SOC content significantly influenced the response of basal respiration to multiple FT (Table 2, Fig. 3A), while soil age significantly affected the response of both basal respiration and the $\mathrm{qCO}_{2}$ (Table 2, Fig. 3B).

\section{Discussion}

MB-C losses after multiple FT events were substantial, with ca. $30-40 \%$ of the MB-C being lost (Fig. 1D); such losses are in correspondence with other studies (Yanai et al. 2004; Schimel et al. 2007). The vast majority of this microbial $\mathrm{C}$ was lost after the first FT event, which is in line with previous studies (Larsen et al. 2002; Walker et al. 2006). Schimel et al. (2007) assumed that the vulnerable part of the microbial biomass is lost after the first FT event, while the remaining microbes appear to be more resistant to additional FT events. In this study, the soil with the highest SOC content showed the highest $\mathrm{C}$ losses from MB-C (Fig. 1D), which corresponds to previous findings from a similar chronosequence study (Rosinger et al., submitted). Because the soil microbial community tends to be more active in high-SOC soils (Barrett and Burke 2000; Allison et al. 2007a), and FT damage was found to be greater when soil microbes were more active and growing (Schimel and Clein 1996), high-SOC soils might be particularly vulnerable to MB-C losses caused by FT. Our data indicate that microbial communities in high-SOC soils could be less resistant to environmental stresses, although a confirmation would require further testing on a larger set of soil samples. Moreover, it needs to be determined whether high-SOC soils on the other hand might be more resilient and thus compensate their losses faster after FT stress (Griffiths and Philippot 2013).

MB-N was also subject to substantial losses after multiple FT events (Song et al. 2017), with ca. 

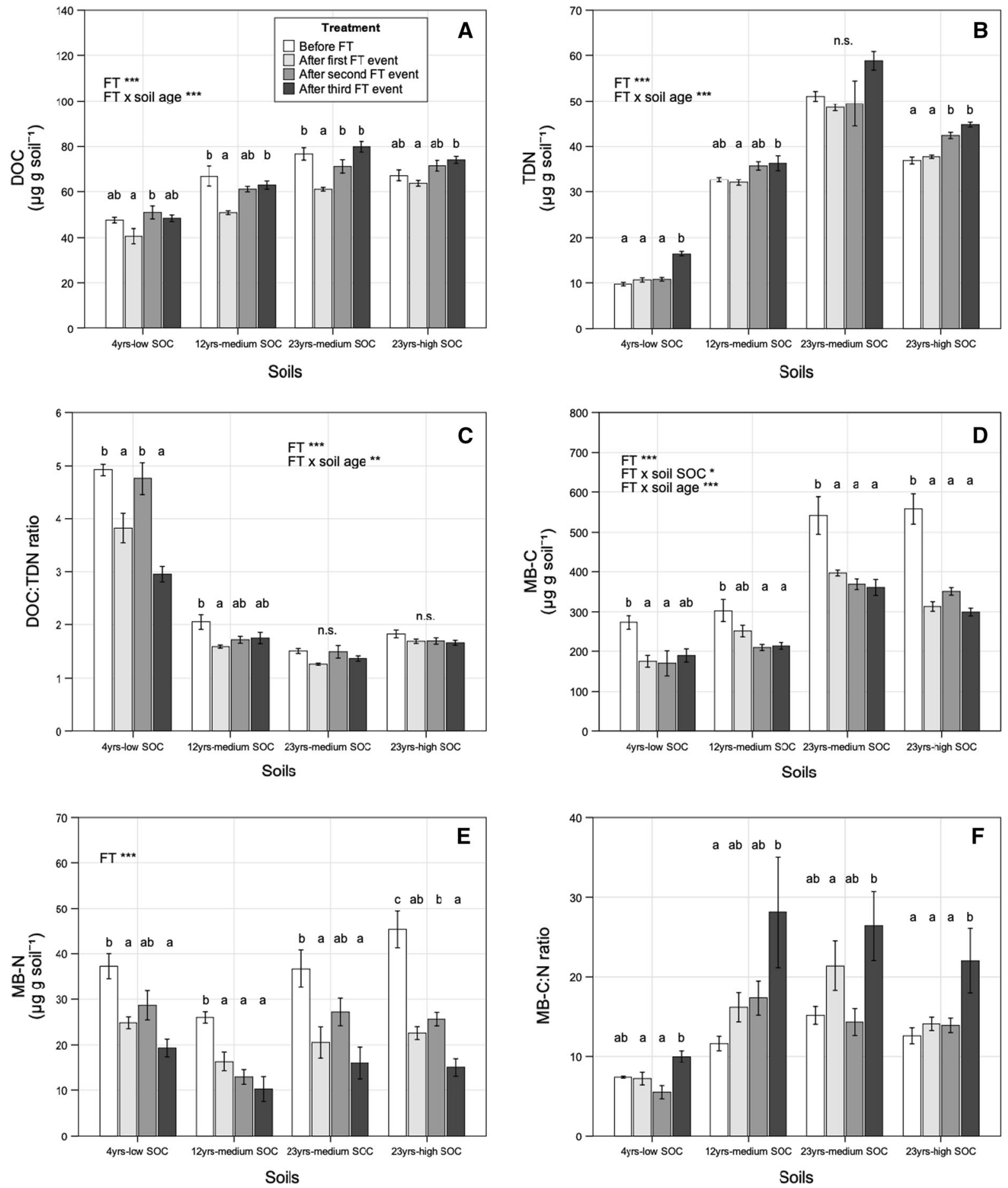

$50-65 \%$ of MB-N being lost in our soils after three FT cycles (Fig. 1E). Just as MB-C, the strongest losses occurred after the first FT event and in the soils with the highest SOC content, further underlining the

vulnerability of high-SOC soils to FT. While initially MB-C and MB-N of the microbial community were strongly correlated, FT caused an immediate and lasting decoupling of MB-C and MB-N contents 
4Fig. 1 The response of A dissolved organic C (DOC), B total dissolved N (TDN), C the DOC:TDN ratio, $\mathbf{D}$ microbial biomass $\mathrm{C}(\mathrm{MB}-\mathrm{C}), \mathbf{E}$ microbial biomass $\mathrm{N}(\mathrm{MB}-\mathrm{N})$ and $\mathbf{F}$ the microbial (MB-C:N) ratio to three freeze-thaw (FT) events in four soils (Soil 1: 4 years, $0.39 \%$ SOC; Soil 2: 12 years, $0.77 \%$ SOC; Soil 3: 23 years, 0.76\% SOC; Soil 4: 23 years, 1.04\% SOC) of a postmining agricultural chronosequence. Bars represent the mean \pm 1 SE $(n=5)$. Significant effects of the FT treatment and significant interaction effects between FT treatment and soil SOC content as well as soil age (as derived from a one-way MANCOVA), respectively, are indicated with $* p<0.05$; $* * \mathrm{p}<0.01 ; * * * \mathrm{p}<0.001$. Different letters above bars indicate significant differences ( $\mathrm{p}<0.05$; post-hoc Tukey test) between FT treatments within each tested soil sample

(Mooshammer et al. 2017; Fig. 2). Such a stoichiometric decoupling can lead to an intensified or a shifted nutrient limitation of soil microorganisms (Sterner and Elser 2002); in chronosequence soils of similar loess substrate of the Inden mine $50 \mathrm{~km}$ south of Garzweiler, Rosinger et al. (submitted) found evidence for a short-term oversaturation of MB-N relative to $-\mathrm{C}$ after a first FT cycle, which would well explain FT-driven $\mathrm{N}$ losses (Matzner and Borken 2008).

It is evident that with soil FT, substantial amounts of $\mathrm{N}$ can be released, and subsequently lost through leaching (Joseph and Henry 2008; Matzner and Borken 2008) or gaseous emissions (Congreves et al. 2018). The magnitude of $\mathrm{N}$ losses that can be directly attributed to FT may amount to $35-65 \%$ of total $\mathrm{N}_{2} \mathrm{O}$ emissions from croplands (Wagner-Riddle et al. 2017). We recorded significant increases in TDN with an increasing number of FT events (Fig. 1B). TDN increases were particularly marked after the second and third FT cycle and in the youngest soil with the lowest SOC content. In natural soil systems, these dissolved $\mathrm{N}$ substrates could be easily lost through leaching. Overall, TDN increases in all four soils after three FT events could only explain $35-50 \%$ of the N reductions in $\mathrm{MB}-\mathrm{N}$, suggesting that the remaining $50-65 \%$ of $\mathrm{N}$ must have been lost via gaseous emissions. This could explain the commonly observed high $\mathrm{N}_{2} \mathrm{O}$ fluxes in agricultural fields with spring thaw (Furon et al. 2008).

FT of soils commonly causes increases in DOC (Song et al. 2017; Matzner and Borken 2008). The released DOC (as well as TDN) after FT is thought to originate from the disruption of plant cells in litter and roots (Su et al. 2010; Campbell et al. 2014), soil macro-aggregates (Kværn $\varnothing$ and Øygarden 2006; Chai et al. 2014), and microbial cells (Larsen et al. 2002). Contrary to this commonly observed pattern, our soils showed 5-25\% reduced DOC contents after the first FT event (Fig. 1A). Only with the second and third FT cycle, DOC contents increased again and reached similar or slightly higher than initial pre-freezing levels at the end of our experiment, suggesting that $\mathrm{C}$ losses via DOC were of minor importance as compared to losses via $\mathrm{CO}_{2}$ emission in our soils (Matzner and Borken 2008).

Along with declining DOC and MB-C after FT, we recorded a significantly increased basal respiration after the first FT event (Sharma et al. 2006; Fig. 3A). Such a $\mathrm{CO}_{2}$ burst is common in soils after FT and assumed to result from the dissimilation of easily accessible organic compounds released by FT (Schimel and Clein 1996; Schimel et al. 2007). Hermann and Witter (2002) showed that the killed microbial biomass was a major contributor to the pool of accessible organic compounds and their subsequent release as $\mathrm{CO}_{2}$ burst after FT. Overall, the increased basal respiration and $\mathrm{qCO}_{2}$ after the first FT together with decreasing DOC and MB-C indicate that a substantial part of the DOC released by FT could not be assimilated, but led to respiratory $\mathrm{C}$ losses by the soil microbial community. This further underlines that substrate availability controls to a substantial degree the respiratory responses to FT (Feng et al. 2007). Basal respiration decreased below initial levels after the second and third FT cycle, which is in agreement to several other studies (Larsen et al. 2002; Koponen et al. 2006; Han et al. 2018). The observed trends in $\mathrm{qCO}_{2}$ resembled the trends of basal respiration rather well, suggesting that the reduced MB-C was responsible for this decline. The metabolic quotient is very responsive to FT (Mooshammer et al. 2017; Fig. 3B). Its sharp increase after the first FT event reflects disproportional dissimilatory (i.e., respiratory) $\mathrm{C}$ losses relative to microbial biomass (Fig. 3B), thus being a sensitive measure of the metabolic state of the soil microbial community (Wardle and Ghani 1995).

We deliberately chose soils that allowed us to disentangle the effects of SOC content and soil age on chemical and microbial responses to multiple FT events, because these factors often auto-correlate in chronosequences, and disentangling their effect is often difficult (Walker et al. 2010). A further important assumption is that sites of different ages follow the 

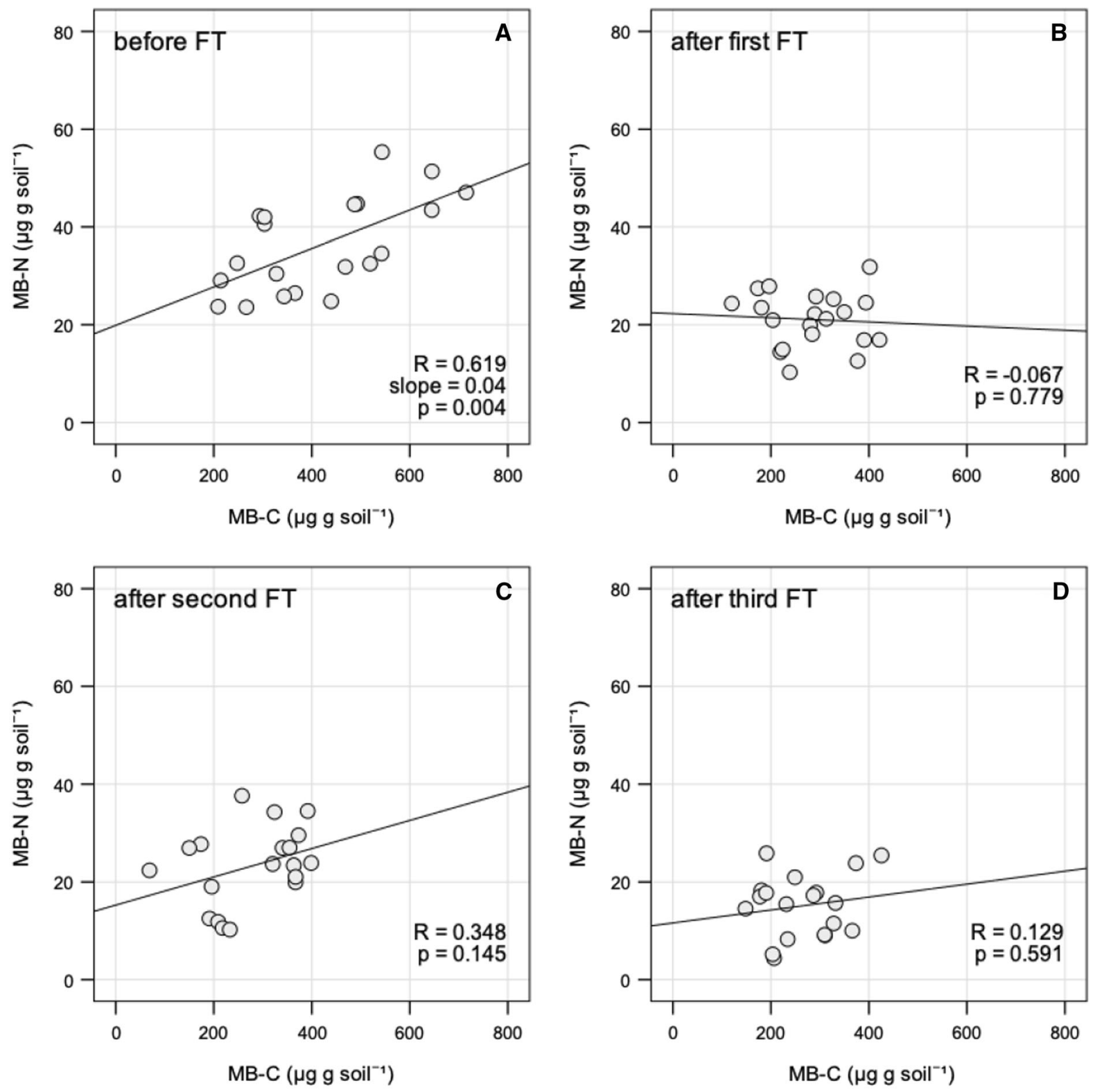

Fig. 2 The relationship between $\mathrm{MB}-\mathrm{C}$ and $\mathrm{MB}-\mathrm{N}$ before freezing (A) and after the first (B), second (C) and third (D) freeze-thaw (FT) event. Linear regression analysis and

same trajectory in soil development. Although farmers do follow area-typical management practices, factors such as fertilizer inputs and/or crop rotations might slightly deviate from field to field. Our analyses showed that soil age was the more important determinant compared to SOC content. While soil age had a significant and strong influence on DOC, TDN, MB-C and both respiratory responses to FT, SOC content

Pearson correlation coefficient (R) was used to test for significant relationships at $\mathrm{p}<0.05(\mathrm{n}=20)$. The dashed lines represent the $95 \%$ confidence interval

explained much less variation and had only a significant influence on $\mathrm{MB}-\mathrm{C}$ and basal respiration (Table 2). High SOC content has been associated with higher microbial activity (Barrett and Burke 2000; Allison et al. 2007a), suggesting that a higher portion of active microbial assemblages is vulnerable to FT events (Schimel and Clein 1996). Studies on soil chronosequences have shown that progressing soil age 


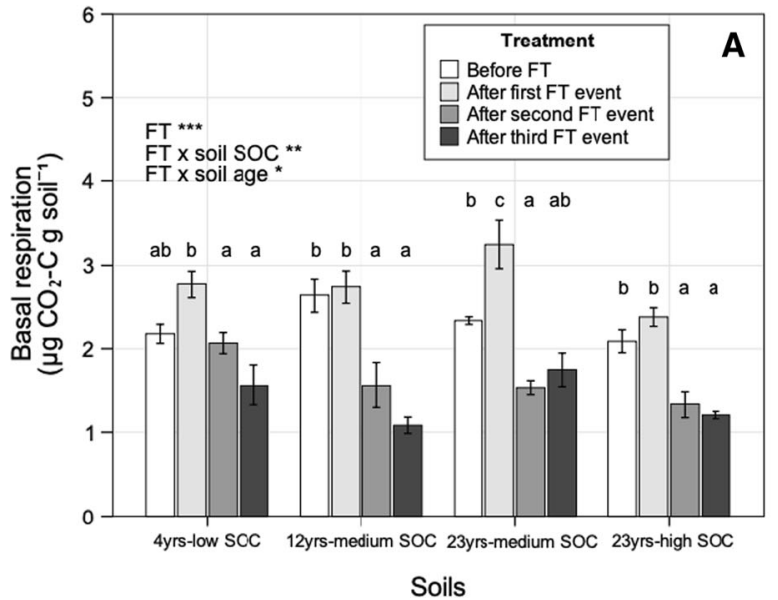

Fig. 3 The response of $\mathbf{A}$ basal respiration and $\mathbf{B}$ the metabolic quotient $\left(\mathrm{qCO}_{2}\right)$ to three freeze-thaw (FT) events in four soils (Soil 1: 4 years, 0.39\% SOC; Soil 2: 12 years, $0.77 \%$ SOC; Soil 3: 23 years, 0.76\% SOC; Soil 4: 23 years, 1.04\% SOC) of a postmining agricultural chronosequence. Bars represent the mean \pm 1 SE $(n=5)$. Significant effects of the FT treatment and

not only implies increasing SOC contents, but also changes in soil organic matter quality (Shi et al. 2006; Egli et al. 2010; Clark et al. 2012; Chaudhuri et al. 2015; Kumar et al. 2018; Khedim et al. 2020), which in turn dictates biogeochemical processes (Shi et al. 2006; Banning et al. 2008). Recently, DelgadoBaquerizo et al. (2020) showed that soil age indeed drives local-scale ecosystem properties associated with biological activity, such as soil $\mathrm{N}: \mathrm{P}$ and $\mathrm{C}: \mathrm{P}$ ratios, microbial biomass, fungal:bacterial dominance or SOC stocks. Thus, microbial responses to FT events may be indirectly linked to soil age via temporal changes in soil biogeochemical characteristics (Yanai et al. 2004; Allison et al. 2005, 2007b; Moore et al. 2010; Delgado-Baquerizo et al. 2020). In line with this, the climatic history of soils can lead to a functional reorganization of the soil microbial community towards more tolerant species (Bardgett and Caruso 2020). Accordingly, a longer history of soil freezing (i.e. older soils) may select for frost-tolerant microbial traits and communities that are physiologically better adapted to FT cycles (Walker et al. 2006; Garcia et al. 2020). Indeed, a recent metagenomic study by Schmidt et al. (2020) showed highly distinct clusters of bacterial communities with soil age in restored loess soils of a comparable soil chronosequence in Inden. Because the restored loess material contains carbonates which disintegrate over time, soil

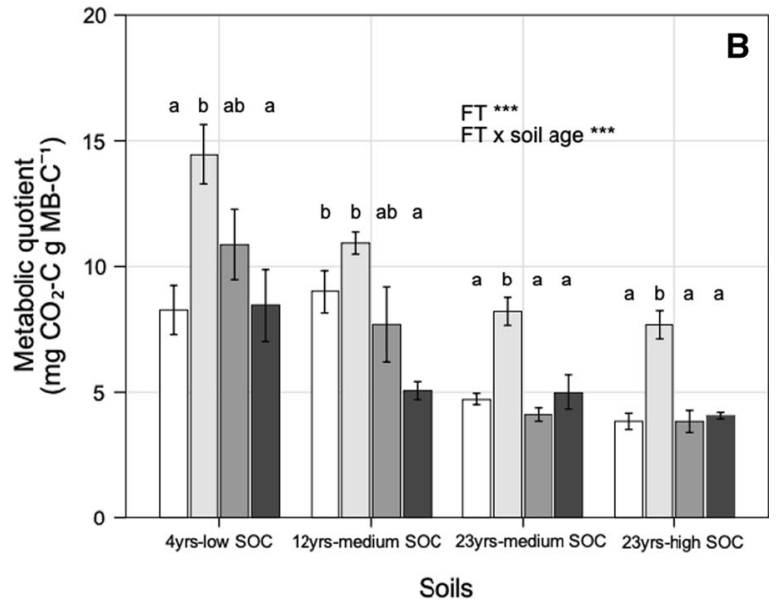

significant interaction effects between FT treatment and soil SOC content as well as soil age (as derived from a one-way MANCOVA), respectively, are indicated with $* p<0.05$; $* * \mathrm{p}<0.01 ; * * * \mathrm{p}<0.001$. Different letters above bars indicate significant differences $(\mathrm{p}<0.05$; post-hoc Tukey test) between FT treatments within each tested soil sample

age and soil $\mathrm{pH}$ were negatively correlated along the chronosequence. Although $\mathrm{pH}$ differences were not strong (8.59 and 8.23 in the youngest and oldest soil, respectively), it is important to mention that soil $\mathrm{pH}$ can have significant effects on nutrient availability (Amelung et al. 2018), microbial community composition (Rousk et al. 2010) and their functions (Kemmitt et al. 2006; Fuentes et al. 2006). Thus, there are likely other parameters covarying with soil age and important in shaping soil microbial responses to FT that we have not captured in our study.

To conclude, this study demonstrated that a single FT event caused a thorough decoupling of MB-C:N stoichiometry. Soils lost a significant proportion of both MB-C and MB-N after the first FT cycle; but while MB-C remained rather unchanged, MB-N continued to decrease with subsequent FT cycles. Our four tested soils lost between 28 and $43 \%$ of MB$\mathrm{C}$ and, even stronger, $47-66 \% \mathrm{MB}-\mathrm{N}$ when exposed to three severe FT events. The MB-C released during the first FT event was mainly lost through respiration and could not be reassimilated into biomass, leading to initially lower DOC values. Increasing DOC with subsequent FT cycles, despite constant levels of MB-C and decreasing MB-N suggest that liberated DOC was less and less metabolized in the subsequent FT cycles. This is corroborated by strongly decreasing rates of $\mathrm{qCO}_{2}$ with subsequent FT cycles, indicating that the 
surviving microbial community showed less and less metabolic activity. The discrepancy of FT-driven MB$\mathrm{N}$ losses to TDN gains was most likely due to gaseous $\mathrm{N}$ losses, potentially driven by a short-term oversaturation of MB-N relative to -C. Our study partly allowed to dissect the importance of soil age and SOC content when explaining variation in soil biochemical responses to multiple FT events, and our results suggest that different mechanisms regulate soil chemical and microbial responses to multiple FT events. Especially soil age turned out to be a significant factor and explained substantial variation in chemical and microbial responses to multiple FT, while SOC content explained much less variation and only affected MB-C and basal respiration. There is an urgent need to better understand these soil processes under future climate change projections. Although conducted on a limited set of samples, our study shows that soil chronosequences can be valuable tools to identify important drivers of microbial responses, such as soil age and SOC content to re-occurring temperature extremes. Future studies should aim to further dissect the processes associated with soil age, which was a major driver of FT-driven changes in soil biochemistry.

Acknowledgements The project was funded by the German Federal Ministry of Education and Research (BMBF) as part of the BonaRes initiative, in the project INPLAMINT: 'Increasing agricultural nutrient-use efficiency by optimizing plant-soilmicroorganism interactions' (Grant No. BMBF-FKZ 031B0508F). The authors thank the INPLAMINT project team, especially Jessica Clayton and Rüdiger Reichel for planning and organizing the soil sampling campaign, Nicolas Brüggemann for leading the consortium. We further thank Gregor Esser and Ernst-Michael Ortmann of the 'Forschungsstelle Rekultivierung' for their logistic support in selecting the chronosequence sites. Special thanks to Irene Brockhaus, Anna Herzog and Conny Thielen for help in soil analyses.

Funding Open Access funding enabled and organized by Projekt DEAL. The project was funded by the German Federal Ministry of Education and Research (BMBF) as part of the BonaRes initiative, in the project INPLAMINT: 'Increasing agricultural nutrient-use efficiency by optimizing plant-soilmicroorganism interactions' (BMBF-FKZ 031B0508F).

Data availability The presented data will be submitted to the BonaRes data repository (https://datenzentrum.bonares.de/dataportal.php).

\section{Declarations}

Conflict of interest The authors declare no conflicts of interest.

Open Access This article is licensed under a Creative Commons Attribution 4.0 International License, which permits use, sharing, adaptation, distribution and reproduction in any medium or format, as long as you give appropriate credit to the original author(s) and the source, provide a link to the Creative Commons licence, and indicate if changes were made. The images or other third party material in this article are included in the article's Creative Commons licence, unless indicated otherwise in a credit line to the material. If material is not included in the article's Creative Commons licence and your intended use is not permitted by statutory regulation or exceeds the permitted use, you will need to obtain permission directly from the copyright holder. To view a copy of this licence, visit http://creativecommons.org/licenses/by/4.0/.

\section{References}

Allison VJ, Miller RM, Jastrow JD, Matamala R, Zak DR (2005) Changes in soil microbial community structure in a tallgrass prairie chronosequence. Soil Sci Soc Am J 69(5):1412-1421

Allison VJ, Condron LM, Peltzer DA, Richardson SJ, Turner BL (2007a) Changes in enzyme activities and soil microbial community composition along carbon and nutrient gradients at the Franz Josef chronosequence, New Zealand. Soil Biol Biochem 39(7):1770-1781

Allison VJ, Yermakov Z, Miller RM, Jastrow JD, Matamala R (2007b) Using landscape and depth gradients to decouple the impact of correlated environmental variables on soil microbial community composition. Soil Biol Biochem 39(2):505-516

Amelung W, Blume HP, Fleige H, Horn R, Kandeler E, KögelKnabner I, Wilke BM (2018) Scheffer/Schachtschabel Lehrbuch der Bodenkunde. Springer, New York

Banning NC, Grant CD, Jones DL, Murphy DV (2008) Recovery of soil organic matter, organic matter turnover and nitrogen cycling in a postmining forest rehabilitation chronosequence. Soil Biol Biochem 40(8):2021-2031

Bardgett RD, Caruso T (2020) Soil microbial community responses to climate extremes: resistance, resilience and transitions to alternative states. Philos Trans R Soc B 375(1794):20190112

Bardgett RD, Freeman C, Ostle NJ (2008) Microbial contributions to climate change through carbon cycle feedbacks. ISME J 2(8):805-814

Barrett JE, Burke IC (2000) Potential nitrogen immobilization in grassland soils across a soil organic matter gradient. Soil Biol Biochem 32(11-12):1707-1716

Campbell JL, Socci AM, Templer PH (2014) Increased nitrogen leaching following soil freezing is due to decreased root uptake in a northern hardwood forest. Glob Change Biol 20(8):2663-2673

Chai YJ, Zeng XB, Bai LY, Su SM, Huang T (2014) Effects of freeze-thaw on aggregate stability and the organic carbon 
and nitrogen enrichment ratios in aggregate fractions. Soil Use Manage 30(4):507-516

Chaudhuri S, McDonald LM, Skousen J, Pena-Yewtukhiw EM (2015) Soil organic carbon molecular properties: effects of time since reclamation in a minesoil chronosequence. Land Degrad Dev 26(3):237-248

Christensen S, Christensen BT (1991) Organic matter available for denitrification in different soil fractions: effect of freeze/thaw cycles and straw disposal. J Soil Sci 42(4):637-647

Clark JD, Plante AF, Johnson AH (2012) Soil organic matter quality in chronosequences of secondary northern hardwood forests in Western New England. Soil Sci Soc Am J 76(2):684-693

Congreves KA, Wagner-Riddle C, Si BC, Clough TJ (2018) Nitrous oxide emissions and biogeochemical responses to soil freezing-thawing and drying-wetting. Soil Biol Biochem 117:5-15

Delgado-Baquerizo M, Reich PB, Bardgett RD, Eldridge DJ, Lambers H, Wardle DA, Berhe AA (2020) The influence of soil age on ecosystem structure and function across biomes. Nat Commun 11(1):1-14

Egli M, Mavris C, Mirabella A, Giaccai D (2010) Soil organic matter formation along a chronosequence in the Morteratsch proglacial area (Upper Engadine, Switzerland). CATENA 82(2):61-69

Feng X, Nielsen LL, Simpson MJ (2007) Responses of soil organic matter and microorganisms to freeze-thaw cycles. Soil Biol Biochem 39(8):2027-2037

Freppaz M, Williams BL, Edwards AC, Scalenghe R, Zanini E (2007) Simulating soil freeze/thaw cycles typical of winter alpine conditions: implications for $\mathrm{N}$ and $\mathrm{P}$ availability. Appl Soil Ecol 35(1):247-255

Fuentes JP, Bezdicek DF, Flury M, Albrecht S, Smith JL (2006) Microbial activity affected by lime in a long-term no-till soil. Soil Tillage Res 88(1-2):123-131

Furon AC, Wagner-Riddle C, Smith CR, Warland JS (2008) Wavelet analysis of wintertime and spring thaw $\mathrm{CO}_{2}$ and $\mathrm{N}_{2} \mathrm{O}$ fluxes from agricultural fields. Agric for Meteorol 148(8-9):1305-1317

Garcia MO, Templer PH, Sorensen PO, Sanders-DeMott R, Groffman PM, Bhatnagar JM (2020) Soil microbes tradeoff biogeochemical cycling for stress tolerance traits in response to year-round climate change. Front Microbiol 11:616

Griffiths BS, Philippot L (2013) Insights into the resistance and resilience of the soil microbial community. FEMS Microbiol Rev 37(2):112-129

Han CL, Gu YJ, Kong M, Hu LW, Jia Y, Li FM, Siddique KH (2018) Responses of soil microorganisms, carbon and nitrogen to freeze-thaw cycles in diverse land-use types. Appl Soil Ecol 124:211-217

Henry HA (2007) Soil freeze-thaw cycle experiments: trends, methodological weaknesses and suggested improvements. Soil Biol Biochem 39(5):977-986

Herrmann A, Witter E (2002) Sources of C and N contributing to the flush in mineralization upon freeze-thaw cycles in soils. Soil Biol Biochem 34(10):1495-1505

Joseph G, Henry HA (2008) Soil nitrogen leaching losses in response to freeze-thaw cycles and pulsed warming in a temperate old field. Soil Biol Biochem 40(7):1947-1953
Kemmitt SJ, Wright D, Goulding KW, Jones DL (2006) pH regulation of carbon and nitrogen dynamics in two agricultural soils. Soil Biol Biochem 38(5):898-911

Khedim N, Cécillon L, Poulenard J, Barré P, Baudin F, Marta S, Ficetola GF (2020) Topsoil organic matter build-up in glacier forelands around the world. Glob Change Biol 27:1662-1677

Koponen HT, Jaakkola T, Keinänen-Toivola MM, Kaipainen S, Tuomainen J, Servomaa K, Martikainen PJ (2006) Microbial communities, biomass, and activities in soils as affected by freeze thaw cycles. Soil Biol Biochem 38(7):1861-1871

Kumar S, Singh AK, Ghosh P (2018) Distribution of soil organic carbon and glomalin related soil protein in reclaimed coal mine-land chronosequence under tropical condition. Sci Total Environ 625:1341-1350

Kværnø SH, Øygarden L (2006) The influence of freeze-thaw cycles and soil moisture on aggregate stability of three soils in Norway. CATENA 67(3):175-182

Larsen KS, Jonasson S, Michelsen A (2002) Repeated freezethaw cycles and their effects on biological processes in two arctic ecosystem types. Appl Soil Ecol 21(3):187-195

Lucas M, Schlüter S, Vogel HJ, Vetterlein D (2019) Soil structure formation along an agricultural chronosequence. Geoderma 350:61-72

Margesin R, Miteva V (2011) Diversity and ecology of psychrophilic microorganisms. Res Microbiol 162(3):346-361

Matzner E, Borken W (2008) Do freeze-thaw events enhance C and $\mathrm{N}$ losses from soils of different ecosystems? A review. Eur J Soil Sci 59(2):274-284

Miura M, Jones TG, Hill PW, Jones DL (2019) Freeze-thaw and dry-wet events reduce microbial extracellular enzyme activity, but not organic matter turnover in an agricultural grassland soil. Appl Soil Ecol 144:196-199

Moore J, Macalady JL, Schulz MS, White AF, Brantley SL (2010) Shifting microbial community structure across a marine terrace grassland chronosequence, Santa Cruz, California. Soil Biol Biochem 42(1):21-31

Mooshammer M, Hofhansl F, Frank AH, Wanek W, Hämmerle I, Leitner S, Zechmeister-Boltenstern S (2017) Decoupling of microbial carbon, nitrogen, and phosphorus cycling in response to extreme temperature events. Sci Adv 3(5):e1602781

Pihlap E, Vuko M, Lucas M, Steffens M, Schloter M, Vetterlein D, Kögel-Knabner I (2019) Initial soil formation in an agriculturally reclaimed open-cast mining area-the role of management and loess parent material. Soil Tillage Res 191:224-237

Risk N, Snider D, Wagner-Riddle C (2013) Mechanisms leading to enhanced soil nitrous oxide fluxes induced by freezethaw cycles. Can J Soil Sci 93(4):401-414

Rousk J, Bååth E, Brookes $\mathrm{PC}$, Lauber CL, Lozupone C, Caporaso JG, Fierer N (2010) Soil bacterial and fungal communities across a $\mathrm{pH}$ gradient in an arable soil. ISME $\mathrm{J}$ 4(10):1340-1351

Scheu S (1992) Automated measurement of the respiratory response of soil microcompartments: active microbial biomass in earthworm faeces. Soil Biol Biochem 24(11):1113-1118 
Schimel JP, Clein JS (1996) Microbial response to freeze-thaw cycles in tundra and taiga soils. Soil Biol Biochem 28(8):1061-1066

Schimel JP, Mikan C (2005) Changing microbial substrate use in Arctic tundra soils through a freeze-thaw cycle. Soil Biol Biochem 37(8):1411-1418

Schimel J, Balser TC, Wallenstein M (2007) Microbial stressresponse physiology and its implications for ecosystem function. Ecology 88(6):1386-1394

Schmid CA, Reichel R, Schröder P, Brüggemann N, Schloter M (2020) 52 years of ecological restoration following a major disturbance by opencast lignite mining does not reassemble microbiome structures of the original arable soils. Sci Total Environ 745:140955

Schmitt A, Glaser B, Borken W, Matzner E (2008) Repeated freeze-thaw cycles changed organic matter quality in a temperate forest soil. J Plant Nutr Soil Sci 171(5):707-718

Sharma S, Szele Z, Schilling R, Munch JC, Schloter M (2006) Influence of freeze-thaw stress on the structure and function of microbial communities and denitrifying populations in soil. Appl Environ Microbiol 72(3):2148-2154

Shi W, Dell E, Bowman D, Iyyemperumal K (2006) Soil enzyme activities and organic matter composition in a turfgrass chronosequence. Plant Soil 288(1-2):285-296

Shivaji S, Prakash JS (2010) How do bacteria sense and respond to low temperature? Arch Microbiol 192(2):85-95

Song Y, Zou Y, Wang G, Yu X (2017) Altered soil carbon and nitrogen cycles due to the freeze-thaw effect: a metaanalysis. Soil Biol Biochem 109:35-49

Sterner RW, Elser JJ (2002) Ecological stoichiometry: the biology of elements from molecules to the biosphere. Princeton University Press, Princeton

Su M, Kleineidam K, Schloter M (2010) Influence of different litter quality on the abundance of genes involved in nitrification and denitrification after freezing and thawing of an arable soil. Biol Fertil Soils 46(5):537-541
Vance ED, Brookes PC, Jenkinson DS (1987) Microbial biomass measurements in forest soils: the use of the chloroform fumigation-incubation method in strongly acid soils. Soil Biol Biochem 19(6):697-702

Wagner-Riddle C, Congreves KA, Abalos D, Berg AA, Brown SE, Ambadan JT, Tenuta M (2017) Globally important nitrous oxide emissions from croplands induced by freezethaw cycles. Nat Geosci 10(4):279-283

Walker VK, Palmer GR, Voordouw G (2006) Freeze-thaw tolerance and clues to the winter survival of a soil community. Appl Environ Microbiol 72(3):1784-1792

Walker LR, Wardle DA, Bardgett RD, Clarkson BD (2010) The use of chronosequences in studies of ecological succession and soil development. J Ecol 98(4):725-736

Wardle DA, Ghani AA (1995) A critique of the microbial metabolic quotient (qCO2) as a bioindicator of disturbance and ecosystem development. Soil Biol Biochem 27(12):1601-1610

Witt C, Gaunt JL, Galicia CC, Ottow JC, Neue HU (2000) A rapid chloroform-fumigation extraction method for measuring soil microbial biomass carbon and nitrogen in flooded rice soils. Biol Fertil Soils 30(5-6):510-519

Yanai Y, Toyota K, Okazaki M (2004) Effects of successive soil freeze-thaw cycles on soil microbial biomass and organic matter decomposition potential of soils. Soil Sci Plant Nutr 50(6):821-829

Yang K, Qin J, Zhao L, Chen Y, Tang W, Han M, Lin C (2013) A multiscale soil moisture and freeze-thaw monitoring network on the third pole. Bull Am Meteor Soc 94(12):1907-2191

Publisher's Note Springer Nature remains neutral with regard to jurisdictional claims in published maps and institutional affiliations. 